\title{
Factors Affecting Success of Laparoscopic Salpingostomy for Tubal Ectopic Pregnancy: One Hundred Case Experience
}

\author{
Basem Hamed*, Amina Nagy \\ Department of Obstetrics and Gynecology, Faculty of Medicine, Zagazig University, Zagazig, Egypt \\ Email: ^basem@zu.edu.eg
}

How to cite this paper: Hamed, B. and Nagy, A. (2019) Factors Affecting Success of Laparoscopic Salpingostomy for Tubal Ectopic Pregnancy: One Hundred Case Experience. Open Journal of Obstetrics and Gynecology, 9, 1549-1557.

https://doi.org/10.4236/ojog.2019.912151

Received: November 7, 2019

Accepted: December 3, 2019

Published: December 6, 2019

Copyright () 2019 by author(s) and Scientific Research Publishing Inc. This work is licensed under the Creative Commons Attribution International License (CC BY 4.0).

http://creativecommons.org/licenses/by/4.0/

\begin{abstract}
Objective: The aim of this work is to predict those patients who will have a successful laparoscopic salpingostomy from those who will be obligated to go for salpingectomy. Methods. This study included 100 cases of diagnosed ectopic pregnancy in low parity women and was prepared for laparoscopic salpingostomy versus salpingectomy. Clinical data were collected from the patients (parity, gestational age and clinical presentation), b-hcg, ultrasound data (vascularity of the mass, viability of fetal pole and site of the ectopic in relation of the ipsilateral ovary), laparoscopic data (presence of mass invasion of the tube, free fluid in Douglas pouch, start of tubal abortion and site of ectopic). Then we started to do salpingostomy on the antimesenteric border of fallopian tube using the spatula with monopolar diathermy and try to remove the conceptus from the tube with hydro dissection and check bleeding from the implantation site, only cauterization of the edges of the tubes at the site of salpingostomy was allowed. The process was called to be successful if no more bleeding from the fallopian tube and tubes were conserved, but it was a failed procedure if too much bleeding from the bed of fallopian tube and laparoscopic salpingectomy was done. Results. 28 cases (28\%) had laparoscopic salpingostomy (success group) and 72 cases (72\%) failed salpingostomy and we went for laparoscopic salpingectomy (failure group). 67 cases with the ectopic in the medial $1 / 2$ of the tube (from which 15 case had salpingostomy and 52 cases had salpingectomy) and 33 cases with ectopic in the lateral 1/2 of the tube (from which 12 cases had salpingostomy and 20 cases had salpingectomy) with no significant difference in both groups ( $\mathrm{P}$ value 0.075 ). 42 case showed start of tubal abortion of which 24 cases (57.2\%) had salpingostomy and 18 cases $(42.8 \%)$ had salpingectomy with highly significant difference between both groups ( $\mathrm{P}$ value 0.000 ). 52 cases during laparoscopy showed invasion of the mass to the fallopian tube and impending tubal rup-
\end{abstract}


ture, from this group 21 cases had salpingostomy and 31 cases had salpingectomy. Conclusions: In tubal pregnancy, presence of non-viable fetal pole together with signs of start of tubal abortion and presence of mild free fluid in Douglas pouch and no mass invasion of the fallopian tube can effectively predict the success of laparoscopic salpingostomy and tubal conservation with no need for salpingectomy in low parity females.

\section{Keywords}

Laparoscopy, Ectopic, Salpingectomy

\section{Introduction}

Ectopic pregnancy is the implantation of products of conception everywhere outside endometrium of the uterine cavity. The prevalence of ectopic pregnancy is about $1 \%-2 \%$ of pregnancies and tubal ectopic pregnancy is the most common type of ectopic gestation [1] [2].

Laparoscopy is the standard surgical approach for ectopic pregnancy; which could be performed by two surgical methods namely salpingectomy (removal of the fallopian tube) and salpingotomy (incising the tube to remove the tubal gestation) [3] [4] [5].

Although both modalities have similar fertility outcomes [6] [7], the possible disadvantage of salpingectomy is the disruption of utero-ovarian circulation and impaired ovarian function due to the proximity of tubal and ovarian arteries at their origin [8]. In addition, in laparoscopic salpingectomy due to the difficult angle of access in the placement of the electrosurgical instruments close to the mesosalpinx, the possibility of impaired ovarian function might increase [9]. In contrast some believe that salpingotomy should be preferred since we use monopolar instrument on the antimesenteric border of the fallopian tube, which is far enough from utero-ovarian vessels conjunction and thus we could achieve more ovarian reserve [10] [11] [12].

\section{Patients and Methods}

The study was conducted in Department of Obstetrics and Gynecology at Faculty of Medicine, Zagazig University in the period between May 2014 and May 2019. This was a prospective cohort study that included 100 case of tubal pregnancy prepared for laparoscopy.

Inclusion criteria were hemodynamically stable tubal pregnancy in low parity women (primigravida and para 1). Exclusion criteria included cases of high parity, hemodynamically unstable, massive pelvic adhesions, cardiac patients or any patient who were unfit for laparoscopy and those who refused salpingostomy after counseling.

The cases were selected from Zagazig University Hospital, obstetrics and gynecology department inpatient ward who were diagnosed to have an ectopic 
pregnancy and prepared for laparoscopic salpingostomy versus salpingectomy according to the intraoperative situation. The following data were revised and tabulated:

1) History taking: including demographic data, complaint and history of present illness obstetric history, co-morbid conditions, review of other systems, past and family history.

2) Clinical examination: including general, chest, heart, abdominal examination and recording of blood pressure.

3) Doppler Ultrasound Assessment:

Three items were revised

a) site of ectopic and the relation to the ipsilateral ovary.

b) presence of pelvic free fluid (mild, moderat or sever).

c) vascularity of the mass.

4) Beta human chorionic gonadotropin ( $\beta$-hCG) level was calculated.

5) The patients were counseled about the benefits and the risk of salpingostomy versus salpingectomy and prepared for laparoscopy.

6) Laparoscopy: under general anaesthesia, three port entry then the following points were revised:

a) site of tubal pregnancy either in the medial half of the tube or in the lateral half of tube (Figure 1).

b) start of tubal abortion (Figure 2).

Figure 3 presence of mass invasion to the fallopian tube and impending tubal rupture.

Then we started to do salpingostomy on the antimesenteric border of fallopian tube using the spatula with monopolar diathermy and try to remove the conceptus from the tube with hydrodissection and check bleeding from the implantation site (Figure 4), only cauterization of the edges of the tubes at the site of salpingostomy was allowed (Figure 5).

The process was called to be successful if no more bleeding from the fallopian tube and tubes were conserved, but it was a failed procedure if too much bleeding from the bed of fallopian tube and laparoscopic salpingectomy was done.

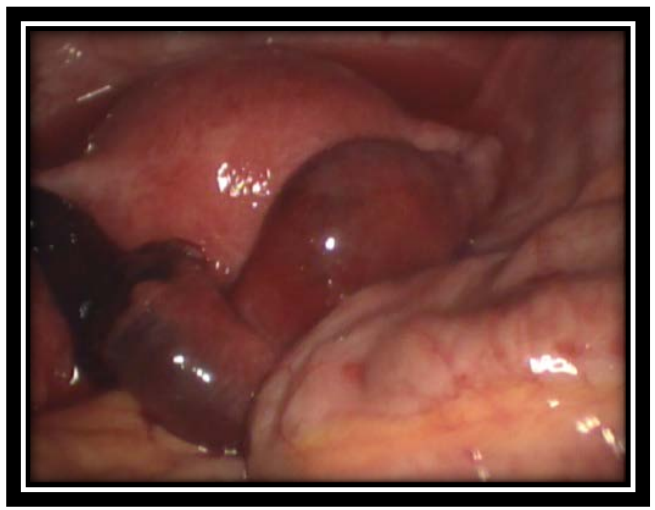

Figure 1. Site of tubal pregnancy (medial or lateral half of the tube). 


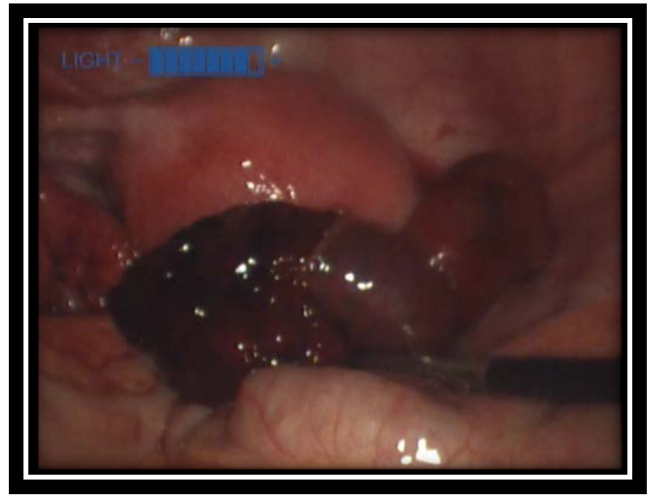

Figure 2. Tubal abortion.

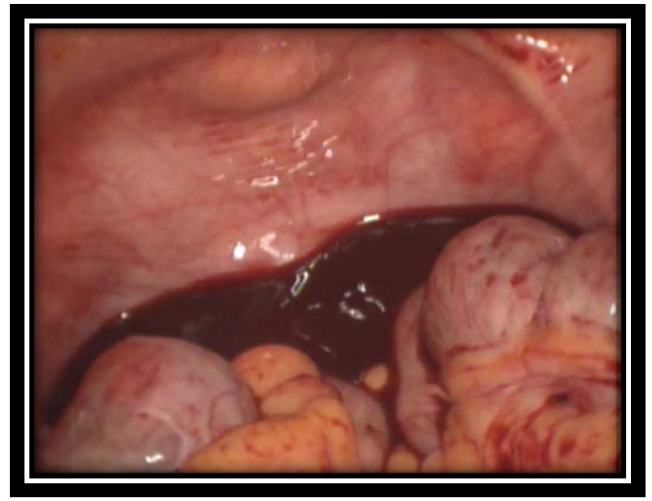

Figure 3. Presence of free fluid.

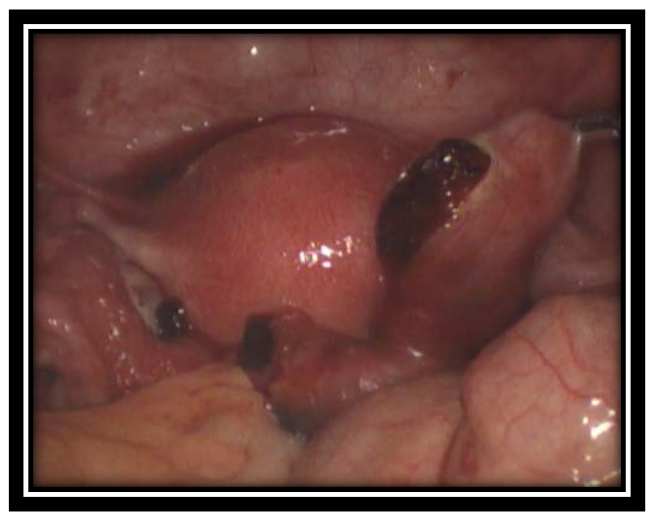

Figure 4. Removal of conceptus from the tube.

\section{Statistical Analysis}

Data were statistically described in terms and mean \pm standard deviation $( \pm S D)$. For comparing categorical data, ChiSquare $\left(\chi^{2}\right)$ test was performed. $\mathrm{P}$ value less than 0.05 were considered statistically significant. All statistical calculations were done using computer program SPSS (Statistical package for the Social Science).

\section{Results}

This study included 100 case of low parity undisturbed tubal pregnancy prepared 


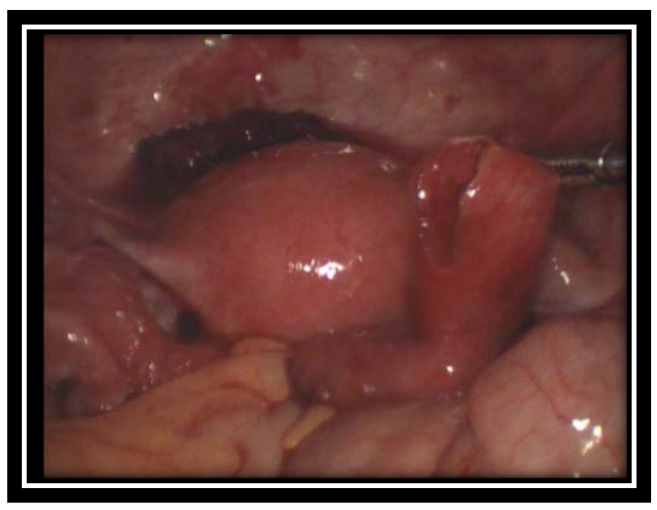

Figure 5. Checking the hemostasis from salpingotomy site.

for laparoscopic salpingostomy versus salpingectomy, 28 cases (28\%) had laparoscopic salpingostomy (success group) and 72 case (72\%) failed salpingostomy and we went for laparoscopic salpingectomy (failure group).

Table 1 discusses the relationship between the clinical data including gestational age, parity and clinical presentation of the patient and the success of salpingostomy. It showed that the mean GA was 6 weeks, 56 cases were P1 and 44 cases were primigravida. 38 case were completely asymptomatic, 46 cases presented with abdominal pain and 38 case presented with vaginal bleeding (some cases presented with both vaginal bleeding and abdominal pain). Regarding to the clinical data, there was no significant difference in both success and failure group.

Table 2 discusses the relationship between the laboratory data including the quantitative b-hcg and ultrasound data including vascularity of the mass (low or high), viability of the fetal pole (viable or not) and site of the ectopic pregnancy (close to the ipsilateral ovary or not).

We concluded that according to quantitative b-hcg, there was no significant difference between both groups. According to the ultrasound finding; vascularity of the mass and site of the ectopic pregnancy has no significant difference between both groups while viability of the fetal pole showed significant difference (patients with viable fetal pole were $38.5 \%$ in the success group and $61.5 \%$ in the failure group).

Table 3 discusses the laparoscopic finding of the studied groups. It showed that 67 case with the ectopic in the medial $1 / 2$ of the tube (from which 15 case had salpingostomy and 52 case had salpingectomy) and 33 case with ectopic in the lateral $1 / 2$ of the tube (from which 12 case had salpingostomy and 20 case had salpingectomy) with no significant difference in both groups. 42 case showed start of tubal abortion from which 24 case (57.2\%) had salpingostomy and 18 cases (42.8\%) had salpingectomy with highly significant difference between both groups. 52 case during laparoscopy showed invasion of the mass to the fallopian tube and impending tubal rupture, from this group 21 cases had salpingostomy and 31 cases had salpingectomy with highly significant difference. 
Table 1. Clinical data in the studied groups.

\begin{tabular}{cccccc}
\hline & $\mathbf{N}$ & $\begin{array}{c}\text { SUCCESS } \\
\text { NO }=28 \\
(\text { mean } \pm \text { SD })\end{array}$ & $\begin{array}{c}\text { FAILED } \\
\text { NO }=72 \\
(\text { mean } \pm \text { SD })\end{array}$ & $\begin{array}{c}\text { TESY OF } \\
\text { SIGNIFCANCE }\end{array}$ & P VALUE \\
\hline Age (years) & 100 & $28.64 \pm 6.73$ & $27.64 \pm 5.73$ & $\mathrm{~T}=-0.748$ & 0.456 \\
GA (weeks) & 100 & $6.00 \pm 1.088$ & $6.11 \pm 0.881$ & $\mathrm{~T}=0.482$ & 0.632 \\
Parity (p1) & 56 & $18(32.1 \%)$ & $38(67.8 \%)$ & $\chi^{2}=1.084$ & 0.298 \\
\hline $\begin{array}{c}\text { Clinical } \\
\text { picture }\end{array}$ & $\mathbf{N}$ & $\mathbf{N}(\%)$ & $\mathbf{N}(\%)$ & $\begin{array}{c}\text { TESY OF } \\
\text { SIGNIFCANCE }\end{array}$ & P VALUE \\
\hline $\begin{array}{c}\text { No symptoms } \\
\text { Abdominal } \\
\text { pain }\end{array}$ & 38 & $8(21.05 \%)$ & $30(78.95 \%)$ & $\chi^{2}=1.467$ & 0.226 \\
$\begin{array}{c}\text { Vaginal } \\
\text { bleeding }\end{array}$ & 38 & $16(34.78 \%)$ & $30(65.22 \%)$ & $\chi^{2}=1.444$ & 0.163 \\
\hline
\end{tabular}

Table 2. Laboratory and ultrasound data of the studied groups.

\begin{tabular}{|c|c|c|c|c|c|}
\hline & $\mathbf{N}$ & $\begin{array}{c}\text { SUCCESS } \\
\text { NO }=\mathbf{2 8}\end{array}$ & $\begin{array}{l}\text { FAILED } \\
\text { NO }=72\end{array}$ & $\begin{array}{c}\text { TEST OF } \\
\text { SIGNIFCAN } \\
\text { CE }\end{array}$ & P VALUE \\
\hline BHCG & 100 & $2986.9 \pm 230$ & $2814 \pm 266$ & $\mathrm{~T}=-0.322$ & 0.764 \\
\hline \multicolumn{6}{|l|}{ US finding } \\
\hline \multicolumn{6}{|l|}{ Vascularity } \\
\hline - Low & 44 & $12(27.3 \%)$ & $32(72.7 \%)$ & $\chi^{2}=0.021$ & 0.886 \\
\hline - high & 56 & $16(28.5 \%)$ & $40(71.4 \%)$ & & \\
\hline \multicolumn{6}{|l|}{ Viability } \\
\hline - viable & 52 & $20(38.4 \%)$ & $32(61.5 \%)$ & $\chi^{2}=5.881$ & 0.015 \\
\hline - nonviable & 48 & $8(16.7 \%)$ & $40(83.3 \%)$ & & \\
\hline \multicolumn{6}{|l|}{ SITE OF MASS } \\
\hline - close to ovary & 28 & $10(35.7 \%)$ & $18(64.3 \%)$ & $\chi^{2}=1.14$ & 0.28 \\
\hline - not close to ovary & 72 & $18(25 \%)$ & $54(75 \%)$ & & \\
\hline
\end{tabular}

Table 3. Laparoscopic finding of the studied groups.

\begin{tabular}{|c|c|c|c|c|c|}
\hline & $\mathrm{N}$ & $\begin{array}{c}\text { SUCCESS } \\
\mathrm{NO}=\mathbf{2 8}\end{array}$ & $\begin{array}{l}\text { FAILED } \\
\mathrm{NO}=72\end{array}$ & $\begin{array}{c}\text { TESY OF } \\
\text { SIGNIFCANCE }\end{array}$ & $\begin{array}{c}\text { P } \\
\text { VALUE }\end{array}$ \\
\hline \multicolumn{6}{|c|}{ Site of the mass } \\
\hline - $\quad$ Medial & 67 & $15(22.4 \%)$ & $52(77.6 \%)$ & $\chi^{2}=3.17$ & 0.075 \\
\hline - Lateral & 33 & $13(39.4 \%$ & $20(60.6 \%)$ & & \\
\hline \multicolumn{6}{|c|}{ Start of tubal abortion } \\
\hline - Yes & 42 & $24(57.2 \%)$ & $18(42.8 \%)$ & $\chi^{2}=30.50$ & 0.000 \\
\hline - no & 58 & $4(6.9 \%)$ & $54(93.1 \%)$ & & \\
\hline \multicolumn{6}{|c|}{ Mass invasion of the tube } \\
\hline - Yes & 52 & $21(40.3 \%)$ & $31(59.7 \%)$ & & \\
\hline - No & 48 & $7(14.6 \%)$ & $41(85.4 \%)$ & $\chi^{2}=8.24$ & 0.004 \\
\hline \multicolumn{6}{|c|}{ Free fluid in Douglaspouch } \\
\hline - no & 54 & $4(7.4 \%)$ & $50(92.3 \%)$ & $\chi^{2}=49.42$ & 0.000 \\
\hline - mild & 28 & $22(78.57 \%)$ & $6(21.4 \%)$ & & \\
\hline - sever & 18 & $2(11.1 \%)$ & $16(88.8 \%)$ & & \\
\hline
\end{tabular}


According to presence of free fluid in Douglaspouch, 54 case with no free fluid (4 in the success group and 50 in the failure group), 28 case with mild free fluid (22 in the success group and 6 in the failure group) 18 case with marked free fluid ( 2 in the success group and 16 in the failure group), it showed high significant difference in both groups according to presence of mild free fluid in Douglas pouch.

\section{Discussion}

In the treatment of tubal ectopic pregnancy (EP), laparoscopic surgery remains the cornerstone of treatment [13]. In the absence of randomized data, the question as to whether surgical treatment should be performed either conservatively (salpingostomy) or radically (salpingectomy) in women with desire for future pregnancy is subject to ongoing debate.

Since the first study demonstrated the potential effectiveness of salpingostomy, this treatment has been compared with salpingectomy in numerous non-randomized studies [14]. Pooled data showed no beneficial effect of salpingostomy on intrauterine pregnancy (IUP) whereas there is an increased risk of repeat EP [15] [16].

Based on these findings, the Royal College of Obstetricians and Gynecologists guideline advises salpingectomy as the preferred standard surgical approach for tubal EP [17]. However, there are good reasons to question this advice. Interpretation of the pooled data is troublesome since many of the original studies failed to report essential details, e.g. time to pregnancy, presence of the desire for future pregnancy and whether subsequent pregnancies occurred either spontaneously or after fertility treatment, such as in vitro fertilization (IVF).

Only few non-randomized studies have taken these matters into account and came to different conclusions [18]-[23]; the IUP rates were higher and the time to an IUP was shorter after salpingostomy compared to salpingectomy. Especially in women with a history of bilateral tubal pathology, salpingostomy offered better IUP rates than salpingectomy, albeit at the cost of an increased risk for repeat EP [18] [19] [20] [22]. In women without a history of tubal pathology this benefit was less clear and also in these women there was an increased risk for repeat EP [20].

There are no randomized controlled trials, which have examined the potential benefits of performing salpingostomy in women with no evidence of contralateral tubal damage as compared to salpingectomy. Despite this lack of evidence, clinicians prefer a salpingectomy over a salpingostomy in the presence of a healthy contralateral tube [23]. This preference is based on the small risk of tubal bleeding in the immediate postoperative period, the potential need for further treatment for persistent trophoblastic and the possibility of a repeat EP in the conserved tube. Moreover, many clinicians prefer a salpingectomy because they find this intervention easier to perform and more quickly done than a salpingostomy. 
Laparoscopic Salpingostomy remains the definitive and universal treatment of ectopic pregnancy in patients who are hemodynamic ally stable and who wish to preserve their fertility otherwise salpingectomy is performed. Laparoscopic salpingotomy may be practiced as conservative surgery for proximal ectopic pregnancy; gestational mass size is not as important and is not a relative contraindication for conservative laparoscopic surgery.

\section{Conclusion}

We concluded from this study that in tubal pregnancy, presence of non-viable fetal pole together with signs of start of tubal abortion and presence of mild free fluid in Douglas pouch and no mass invasion of the fallopian tube can effectively predict the success of laparoscopic salpingostomy and tubal conservation with no need for salpingectomy in low parity females.

\section{Conflicts of Interest}

The authors declare no conflicts of interest regarding the publication of this paper.

\section{References}

[1] Centers for Disease Control and Prevention (CDC) (1995) Ectopic Pregnancy-United States, 1990-1992. Morbidity and Mortality Weekly Report, 44, 46-48.

[2] Goldner, T.E., et al. (1993) Surveillance for Ectopic Pregnancy-United States, 1970-1989. The Cochrane Database of Systematic Reviews, 42, 73-85.

[3] Hajenius, P.J., et al. (2007) Interventions for Tubal Ectopic Pregnancy. The Cochrane Database of Systematic Reviews, No. 1, CD000324. https://doi.org/10.1002/14651858.CD000324.pub2

[4] Parker, J., et al. (1997) Laparoscopic Surgical Treatment of Ectopic Pregnancy: Salpingectomy or Salpingostomy? Australian and New Zealand Journal of Obstetrics and Gynaecology, 37, 115-117. https://doi.org/10.1111/j.1479-828X.1997.tb02232.x

[5] Thornton, K., et al. (1991) Linear Salpingostomy for Ectopic Pregnancy. Obstetrics and Gynecology Clinics of North America, 18, 95-109.

[6] Fernandez, H., et al. (2013) Fertility after Ectopic Pregnancy: The Demeter Randomized Trial. Human Reproduction, 28, 1247-1253.

https://doi.org/10.1093/humrep/det037

[7] Mol, F., et al. (2014) Salpingotomy versus Salpingectomy in Women with Tubal Pregnancy (ESEP Study): An Open-Label, Multicentre, Randomised Controlled Trial. The Lancet, 383, 1483-1489. https://doi.org/10.1016/S0140-6736(14)60123-9

[8] Ye, X.-P., Yang, Y.-Z. and Sun, X.-X. (2015) A Retrospective Analysis of the Effect of Ovarian Reserve after Laparoscopic Salpingectomy Compared with Laparoscopic Salpingotomy in Patients with Tubal ... 971 Salpingectomy on Serum Anti-Müllerian Hormone Level and Ovarian Reserve. American Journal of Obstetrics and Gynecology, 212, 53.e1-53.e10. https://doi.org/10.1016/j.ajog.2014.07.027

[9] Chan, C., et al. (2003) Impaired Ovarian Blood Flow and Reduced Antral Follicle Count Following Laparoscopic Salpingectomy for Ectopic Pregnancy. Human Reproduction, 18, 2175-2180. https://doi.org/10.1093/humrep/deg411

[10] DeCherney, A.H., et al. (1982) Salpingostomy for Ectopic Pregnancy in the Sole Pa- 
tent Oviduct: Reproductive Outcome. Fertility and Sterility, 37, 619-622. https://doi.org/10.1016/S0015-0282(16)46271-0

[11] DeCherney, A.H. and Diamond, M.P. (1987) Laparoscopic Salpingostomy for Ectopic Pregnancy. Obstetrics \& Gynecology, 70, 948-950.

[12] Fujishita, A., et al. (2004) Laparoscopic Salpingotomy for Tubal Pregnancy: Comparison of Linear Salpingotomy with and without Suturing. Human Reproduction, 19, 1195-1200. https://doi.org/10.1093/humrep/deh196

[13] Hajenius, P.J., Mol, F., Mol, B.W., Bossuyt, P.M., Ankum, W.M. and van der Veen, F. (2007) Interventions for Tubal Ectopic Pregnancy. Cochrane Database of Systematic Reviews, No. 2, CD000324. https://doi.org/10.1002/14651858.CD000324.pub2

[14] Stromme, W.B., McKelvey, J.L. and Adkins, C.D. (1962) Conservative Surgery for Ectopic Pregnancy. Obstetrics \& Gynecology, 19, 294-301.

[15] Clausen, I. (1996) Conservative versus Radical Surgery for Tubal Pregnancy. Acta Obstetricia et Gynecologica Scandinavica, 75, 8-12. https://doi.org/10.3109/00016349609033276

[16] Yao, M. and Tulandi, T. (1997) Current Status of Surgical and Nonsurgical Management of Ectopic Pregnancy. Fertility and Sterility, 67, 421-433. https://doi.org/10.1016/S0015-0282(97)80064-7

[17] Royal College of Obstetricians and Gynaecologists (2004) Guideline No. 21. The Management of Ectopic Pregnancy. RCOG Press.

[18] Silva, P., Schaper, A. and Rooney, B. (1993) Reproductive Outcome after 143 Laparoscopic Procedures for Ectopic Pregnancy. Fertility and Sterility, 81, 710-715.

[19] Job-Spira, N., Bouyer, J., Pouly, J.L., Germain, E., Coste, J., Aublet-Cuvelier, B. and Fernandez, H. (1996) Fertility after Ectopic Pregnancy: First Results of a Population-Based Cohort Study in France. Human Reproduction, 11, 99-104. https://doi.org/10.1093/oxfordjournals.humrep.a019048

[20] Mol, B.W.J., Matthijse, H.C., Tinga, D.J., Huynh, T., Hajenius, P.J., Ankum, W.M., Bossuyt, P.M.M. and Veen van der, F. (1998) Fertility after Conservative and Radical Surgery for Tubal Pregnancy. Human Reproduction, 13, 1804-1809. https://doi.org/10.1093/humrep/13.7.1804

[21] Bouyer, J., Job-Spira, N., Pouly, J.L., Coste, J., Germain, E. and Fernandez, H. (2000) Fertility Following Radical, Conservative-Surgical or Medical Treatment for Tubal Pregnancy: A Population-Based Study. BJOG, 107, 714-721. https://doi.org/10.1111/j.1471-0528.2000.tb13330.x

[22] Bangsgaard, N., Lund, C.O., Otessen, B. and Nilas, L. (2003) Improved Fertility Following Conservative Surgical Treatment of Ectopic Pregnancy. British Journal of Obstetrics and Gynaecology, 110, 765-770. https://doi.org/10.1111/j.1471-0528.2003.02253.x

[23] Rulin, M.C. (1995) Is Salpingostomy the Surgical Treatment of Choice for Unruptured Tubal Pregnancy? Obstetrics \& Gynecology, 86, 1010-1013. https://doi.org/10.1016/0029-7844(95)00330-T 